\title{
Lei de Inovação do Estado do Paraná: uma visão sistêmica focada em negócio.
}

Júlio C. Felix*

Resumo: O presente artigo trata da legislação que ampara a atividade econômica nos estados e municípios, em especial àquelas existentes no Estado do Paraná. O artigo apresenta um breve panorama das leis existentes, buscando sistematizar a legislação e apresentar o status desse movimento no País. Em seguida detêm-se sobre a Lei do Estado do Paraná apresentando seus principais aspectos. Por fim faz-se uma síntese dos desafios e próximos passos da regulamentação dessa importante base legal para a atividade empreendedora.

Palavras-chave: Inovação, Desenvolvimento regional, Lei de Inovação.

Classificação JEL: O31; O38; O21.

\footnotetext{
* Especialização, Diretor-Presidente do Instituto de Tecnologia do Paraná (Tecpar) - jfelix@tecpar.br
} 


\section{Introdução}

A dinâmica competitiva atual é cada vez mais focada na inovação como cerne de qualquer negócio. Criar novos produtos, implementar processos mais eficazes, organizar de maneira inédita as rotinas organizacionais ou, ainda, reduzir os impacto das operações sobre o ambiente e a sociedade, têm sido as estratégias das empresas líderes em seus segmentos.

O destaque tem crescido, pois se observa uma relação direta entre os países que mais têm evoluído em termos econômicos e sociais e aqueles onde os processos inovativos estão mais arraigados na população. Nãoé mera coincidência que a Alemanha, por exemplo, seja o arrimo da Europa nessas décadas de turbulências financeiras. Ou a China, que movimenta a economia mundial e ao mesmo tempo tem investido maciçamente em Pesquisa, Desenvolvimento e Inovação (PD\&I). De acordo com Alvarez (2010), a inovação é um tema a ser estudado e avaliado tanto por empresas quanto pelos governos. Diz respeito aos governos pela sua capacidade de poder gerar valor, estimular ou sustentar o crescimento econômico. E diz respeito às empresas, pois elas estão ligadas às questões da competitividade.

Vale destacar nesse cenário o papel dos países emergentes. O desenvolvimentoeconômico desses países retroalimenta a competição de mercados maduros, "pressionando por inovação e eficiência os produtos tradicionalmente estabelecidos nesses espaços." (Alvarez, 2010, p. 37). O Brasil vive um momento especial nesse contexto, por vezes pouco alvissareiro. A manutenção da relativa estabilidade econômica e política têm propiciado oportunidades de negócio para os empreendedores. Somam-se a isso dois grandes eventos internacionais fortemente relacionados à disponibilidade de infraestrutura. Um cenário global reticente a novidades financistas ou agressões irresponsáveis à sustentabilidade. Enfim, prospectam-se ao menos três ou quatro anos de prosperidade, caso as oportunidades sejam aproveitadas de modo eficaz.

Outro ponto a ser considerado é relativo à crise global, cujos contornos ainda não são plenamente conhecidos e cujos reflexos sobre a produção e o comércio internacional são uma incógnita quase absoluta. O fato é que o multilateralismo que criou a ilusão da economia global, com um fluxo de comércio aberto e interdependente entre as nações, também está em crise, trazendo o fantasma do novo protecionismo, junto com sua ferramenta mais perversa: as barreiras não tarifárias ao comércio.

Nesse contexto, conquanto vão se multiplicar as exigências metrológicas e normativas, o acesso a mercados passa a depender, como nunca da capacidade das empresas em colocar de forma contínua novos produtos, de alta qualidade e desempenho e ainda sustentáveis e socialmente responsáveis. Esse fato aumenta substantivamente o desafio da inovação como fator de competitividade das empresas.

Em síntese, produtos realmente inovadores, ambientalmente adequados e socialmente responsáveis podem romper a barreira protecionista que recrudesce e torna-se cada vez mais acirrada. 
Nesta conjuntura, a existência de um arcabouço legal que impulsione a inovação no Brasil é mais do que uma necessidade, mas uma imposição da economia. A profusão de legislações estaduais e até mesmo municipais está alicerçando o caminho para os próximos anos de desenvolvimento nacional. Assim, é fundamental manter ativa a discussão sobre o tema e difundir as melhores práticas observadas nos locais onde a Lei de Inovação já esta sendo utilizada. É igualmente importante fomentar as oportunidades de melhoria nos locais onde a lei ainda está em processo de implementação ou atualização.

Entretanto é fundamental destacar que somente uma legislação que estimule a inovação não é suficiente. Não basta porque as instituições brasileiras, notadamente as de P\&D, e nessas as públicas, estão com quadros profissionais insuficientes, mal remunerados e sem as competências adequadas para prover soluções à sociedade. Estão tolhidas de sua liberdade decisória pela onipresença de mecanismos de controle avessos aos desafios da inovação e dos riscos inerentes a essa atividade. Mecanismos esses que lamentavelmente não estão interessados em rever suas práticas e, portanto, inovar também. Essas instituições são fundamentais, pois compõem um sistema de inovação, que precisa operar de maneira coesa para efetivamente resultar em desenvolvimento para o País.

O pior cenário, caso não haja uma inovação nesse aspecto de nosso sistema de inovação será o de instituições de $\mathrm{P} \& \mathrm{D}$ inibidas no relacionamento com as empresas. E hoje já se tem boa clareza de que o processo inovativo não ocorre intramuros em uma empresa, nem exclusivamente na relação universidadeempresa. A inovação é um processo aberto e é cada vez mais fruto das redes de cooperação envolvendo diversos atores de diversos países. Assim ter excelência científica e competência tecnológica para participar ativamente desse processo é indispensável e até mesmo decisivo. Complementarmente é preciso desenvolver as competências para gerenciar essas estruturas de rede altamente complexas.

Esse texto se divide em seis partes, incluindo essa introdução e 2 seções, uma com as considerações finais e outra com as referências utilizadas no trabalho. A seção 2 comenta o panorama atual das Leis de Inovação no país. A seção 3 destaca o caso a Lei Estadual de Inovação do Paraná, que está em processo de análise crítica para complementar sua regulamentação.

\section{0 panorama das leis de inovação no brasil}

A participação do Estado para estimular a inovação no país se deu, dentre outros instrumentos disponibilizados, por meio da Lei de Inovação $\left(\mathrm{n}^{\circ}\right.$ 10.973/2004). Com o intuito de construir ambientes próprios e cooperativos de inovação, propôs a criação de um marco regulatório para estimular o patenteamento e transferência de tecnologia de universidades públicas e institutos de pesquisa para as empresas privadas. A Lei de Inovação, contudo, foi editada com uma grave limitação, que é impedimento constitucional para que a União possa legislar de forma concorrente com estados e municípios em matéria de ciência, tecnologia, pesquisa e desenvolvimento; tal restrição, entretanto, está 
sendo revista com a Proposta de Emenda Constitucional - PEC, n 290/2013, que se encontra em fase de votação no Plenário da Câmara dos Deputados; a PEC 290/2013 amplia o alcance dos artigos 23, 24, 218 e 219 da Constituição Federal, explicitando mais claramente ciência, tecnologia e inovação.

Embora essa iniciativa tenha sido essencial para estimular e gerir o conhecimento e a inovação como motora da competitividade e do desenvolvimento, ainda existem diversos obstáculos para se inovar no Brasil. Para atender necessidades específicas de cada estado, se fazem necessárias leis estaduais, pensadas e formuladas olhando a realidade local e, principalmente, lançando mão de recursos e facilidades locais. De acordo com Taylor (2007), alguns países têm mais sucesso que outros no progresso tecnológico; uma tendência observada é que a governos descentralizados são amplamente vistos como mais ágeis, competitivos e bem estruturados para adaptarem-se ao vento inovador da destruição criadora. Nesse âmbito a regulamentação local da inovação representa um arcabouço favorável para o processo brasileiro. Ou seja, os estados tendem a ter suas próprias leis e ainda as fundações de amparo à pesquisa, encarregadas de inserir mais recursos nos sistemas locais de inovação.

No momento da realização deste trabalho, 16 Estados brasileiros já possuíam sua Lei de Inovação aprovada e 5 Estados encontravam-se já com a minuta da lei em discussão. Os demais Estados da Federação não apresentam ainda Lei de Inovação em nenhum estágio, ou não havia informações disponíveis. A figura 1 sintetiza o quadro brasileiro. 
Quadro 1 - Panorama brasileiro das Leis Estaduais de Inovação no Brasil 2014

\begin{tabular}{|c|c|c|c|}
\hline Estado & $\begin{array}{c}\text { Minuta de } \\
\text { Projeto de Lei }\end{array}$ & Lei Estadual & Decreto \\
\hline Alagoas & & $\begin{array}{l}\text { Lei } \mathrm{n}^{\circ} 7.117 \text {, de } 12 \text { de } \\
\text { novembro de } 2009\end{array}$ & \\
\hline Amapá & & & \\
\hline Amazonas & & $\begin{array}{l}\text { Lei Estadual n }{ }^{\circ} 3.095 \text {, de } 17 \\
\text { de novembro de } 2006\end{array}$ & \\
\hline Bahia & & $\begin{array}{l}\text { Lei } n^{\circ} 11.174 \text { de } 09 \text { de } \\
\text { dezembro de } 2008\end{array}$ & \\
\hline Ceará & & $\begin{array}{l}\text { Lei } \mathrm{n}^{\circ} 14.220 \text {, de } 16 \text { de } \\
\text { outubro de } 2008\end{array}$ & \\
\hline Distrito Federal & $\begin{array}{l}\text { Minuta de Projeto } \\
\text { de Lei }\end{array}$ & & \\
\hline Goiás & & $\begin{array}{l}\text { Lei } n^{\circ} 16.922 \text {, de } 08 \text { de } \\
\text { fevereiro de } 2010\end{array}$ & \\
\hline Maranhão & $\begin{array}{l}\text { Minuta de Projeto } \\
\text { de Lei }\end{array}$ & & \\
\hline Mato Grosso & & $\begin{array}{l}\text { Lei Complementar } \mathrm{n}^{\circ} 297 \text {, } \\
\text { de } 7 \text { de janeiro de } 2008\end{array}$ & \\
\hline Mato Grosso do Sul & & & $\begin{array}{l}\text { Decreto Legislativo } \\
\mathrm{N}^{\circ} 489 \text { de } 16 \text { de } \\
\text { novembro de } 2010\end{array}$ \\
\hline Minas Gerais & & $\begin{array}{l}\text { Lei } n^{0} 17.348 \text {, de } 17 \text { de } \\
\text { janeiro de } 2008\end{array}$ & \\
\hline Pará & $\begin{array}{l}\text { Minuta de Projeto } \\
\text { de Lei }\end{array}$ & & \\
\hline Paraíba & $\begin{array}{l}\text { Minuta de Projeto } \\
\text { de Lei }\end{array}$ & & \\
\hline Paraná & & $\begin{array}{l}\text { Lei } n^{\circ} 17.314 \text {, de } 24 \text { de } \\
\text { Setembro de } 2012\end{array}$ & $\begin{array}{l}\text { Decreto } 7359 \text {, de } \\
\text { fevereiro de } 2013\end{array}$ \\
\hline Pernambuco & & $\begin{array}{l}\text { Lei } n^{\circ} 13.690 \text {, de } 16 \text { de } \\
\text { dezembro de } 2008\end{array}$ & $\begin{array}{l}\text { Decreto } 33.433 \text {, de } \\
29 \text { de maio de } 2009\end{array}$ \\
\hline Piauí & $\begin{array}{l}\text { Minuta de Projeto } \\
\text { de Lei }\end{array}$ & & \\
\hline Rio de Janeiro & & $\begin{array}{l}\text { Lei } \mathrm{n}^{\circ} 5.361 \text {, de } 29 \text { de } \\
\text { dezembro de } 2008\end{array}$ & $\begin{array}{l}\text { Decreto } \mathrm{n}^{\circ} 42.302 \\
\text { de } 12 \text { de fevereiro } \\
\text { de } 2010\end{array}$ \\
\hline Rio Grande do Norte & & $\begin{array}{l}\text { Lei Complementar n }{ }^{\circ} 478 \text {, } \\
\text { de } 27 \text { de dezembro de } 2012 \text {. }\end{array}$ & \\
\hline Rio Grande do Sul & & $\begin{array}{l}\text { Lei n }{ }^{\circ} 13.196 \text {, de } 13 \text { de } \\
\text { julho de } 2009\end{array}$ & \\
\hline Santa Catarina & & $\begin{array}{l}\text { Lei } n^{\circ} 14.348 \text {, de } 15 \text { de } \\
\text { janeiro de } 2008\end{array}$ & $\begin{array}{l}\text { Decreto } \mathrm{n}^{\circ} 2.372 \text {, de } \\
9 \text { de junho de } 2009\end{array}$ \\
\hline São Paulo & & $\begin{array}{l}\text { Lei Complementar n }{ }^{\mathrm{o}} 1049 \text {, } \\
\text { de } 19 \text { de junho de } 2008\end{array}$ & $\begin{array}{l}\text { Decreto } n^{\circ} 54.690, \\
\text { de } 18 \text { de agosto de } \\
2009\end{array}$ \\
\hline Sergipe & & $\begin{array}{l}\text { Lei n }{ }^{\circ} 6.794, \text { de } 02 \text { de } \\
\text { dezembro de } 2009\end{array}$ & \\
\hline Tocantins & & $\begin{array}{l}\text { Lei } \mathrm{n}^{\circ} 2.458 \text {, de } 5 \text { de julho } \\
\text { de } 2011\end{array}$ & \\
\hline
\end{tabular}

Fonte: Elaboração Própria 
Também existem 8 Leis Municipais de Inovação aprovadas e 5 Leis com Minuta escrita em discussão. O tabela 2 apresenta a síntese desse andamento.

Quadro 2 - Panorama brasileiro das Leis Municipais de Inovação no Brasil 2014

\begin{tabular}{|c|c|c|c|}
\hline Estado & $\begin{array}{c}\text { Minuta de } \\
\text { Projeto de Lei }\end{array}$ & Lei Municipal & Decreto \\
\hline Espírito Santo (Vitória) & & $\begin{array}{l}\text { Lei Municipal } n^{0} 7.871 \text {, } \\
\text { de } 21 \text { de dezembro de } \\
2009\end{array}$ & \\
\hline Minas Gerais (Itajubá) & & $\begin{array}{l}\text { Lei Municipal n }{ }^{\circ} 2.677 \text {, de } \\
11 \text { de junho de } 2.008\end{array}$ & \\
\hline Minas Gerais (Viçosa) & & $\begin{array}{l}\text { Lei Municipal no } 2.204 \text { de } \\
2011\end{array}$ & \\
\hline Paraná (Curitiba) & $\begin{array}{l}\text { Minuta de Projeto } \\
\text { de Lei }\end{array}$ & & \\
\hline Paraná (Londrina) & $\begin{array}{l}\text { Minuta de Projeto } \\
\text { de Lei }\end{array}$ & & \\
\hline Paraná (Maringá) & $\begin{array}{l}\text { Minuta de Projeto } \\
\text { de Lei }\end{array}$ & & \\
\hline Paraná (Francisco Beltrão) & $\begin{array}{l}\text { Minuta de Projeto } \\
\text { de Lei }\end{array}$ & & \\
\hline $\begin{array}{l}\text { Rio Grande do Sul (Porto } \\
\text { Alegre) }\end{array}$ & & $\begin{array}{l}\text { Lei Complementar n }{ }^{\circ} 721 \text {, } \\
\text { de } 29 \text { de Novembro de } 2013\end{array}$ & \\
\hline $\begin{array}{l}\text { Rio Grande do Sul (Santa } \\
\text { Maria) }\end{array}$ & & $\begin{array}{l}\text { Lei Municipal n }{ }^{\circ} 5306 \text {, de } 04 \\
\text { de maio de } 2010\end{array}$ & \\
\hline $\begin{array}{l}\text { Santa Catarina } \\
\text { (Florianópolis) }\end{array}$ & & $\begin{array}{l}\text { Lei Complementar } \mathrm{n}^{\circ} 432 \text {, } \\
\text { de } 07 \text { de Maio de } 2012\end{array}$ & $\begin{array}{l}\text { Decreto } \mathrm{n}^{\circ} 10.315 \text {, } \\
\text { de } 27 \text { de setembro } \\
\text { de } 2012 \text {. }\end{array}$ \\
\hline Santa Catarina (Chapecó) & & $\begin{array}{l}\text { Lei } \mathrm{n}^{\circ} 6476, \text { de } 15 \text { de } \\
\text { outubro de } 2013 .\end{array}$ & \\
\hline São Paulo (São Paulo) & $\begin{array}{l}\text { Minuta de Projeto } \\
\text { de Lei }\end{array}$ & & \\
\hline $\begin{array}{l}\text { São Paulo (São Bernardo } \\
\text { do Campo) }\end{array}$ & & $\begin{array}{l}\text { Lei n }{ }^{\circ} 6243 \text {, de } 26 \text { de } \\
\text { dezembro de } 2012\end{array}$ & \\
\hline
\end{tabular}

Fonte: Elaboração Própria

Pelos quadros, é possível notar que a existência de legislação para Inovação guarda forte relação com o estágio de desenvolvimento social e industrial. Os estados do Sul e Sudeste encontram-se com todos os seus integrantes com leis em vigor. A tarefa de cobrir a totalidade das Unidades da Federação com legislações sobre Inovação torna-se cada vez menos árdua, pois as experiências existentes emulam o caminho a ser percorrido pelos Estados retardatários. Entretanto, retardar ainda mais a instituição da Lei de Inovação recrudesce as deficiências competitivas do tecido empresarial das regiões, e isso agrava as diferenças de estágio de desenvolvimento.

Os agentes integrantes dos Sistemas Regionais de Inovação, onde as Leis de Inovação estão em vigor, podem promover a difusão do conhecimento gerado e estimular os atores nos outros estados a se mobilizarem para ter também sua legislação. 
Outro ponto a ser considerado refere-se à lógica dessas leis: a Federal objetivou destravar a relação entre entes públicos de $\mathrm{C} \& \mathrm{~T}$ e as empresas, relação essa tolhida por amarras burocráticas totalmente impeditivas do processo de transferência de tecnologia e do estímulo à geração de idéias que possam ser levadas às empresas.

Vale destacar que a Lei de Inovação por si só seria insuficiente se não estivesse associadas a outros estímulos às empresas, como por exemplo, a Lei do Bem (Lei ${ }^{\circ}$ 11.196/2005), que traz incentivos fiscais para a atividade empreendedora, bem como outros casos que têm sido usados pelo setor privado.

Essa construção tem que estar também refletida nas legislações locais (estados e municípios), de forma a se criar os estímulos reais ao processo inovativos nas empresas.

Outro aspecto indispensável é o do uso do poder de compra do estado para estimular o desenvolvimento de produtos inovadores; tal estratégia tem sido empregada com êxito em muitos países e mesmo no caso brasileiro já existe a legislação para isso (Lei $\left.{ }^{\circ} 12.349 / 2010\right)$. Outro instrumento importante é a Lei $\mathrm{n}^{\circ}$ 12.431/2011 que abre a possibilidade de emissão de debêntures para produção econômica intensiva em pesquisa, desenvolvimento e inovação, acompanhando a estratégia de outros países quanto ao financiamento de longo prazo.

A própria Lei de Inovação (10.793/2004) está sendo revista e bastante ampliada no Congresso Nacional (Projeto de Lei, PL nº 2.177/2011 na Câmara e Projeto de Lei do Senado, PLS nº 619/2011)

\section{A Lei de Inovação: o caso do Estado do Paraná}

A Inovação e o conhecimento, como puderam ser vistos até agora, se tornaram as forças motrizes do desenvolvimento regional sustentável. Com isso, as políticas meramente transferidoras de renda não são mais suficientes para garantir a fortaleza dos Estados do Brasil. É certo que essas políticas ainda são necessárias em algumas regiões, mas para a grande maioria delas, é preciso a proposição de instrumentos que incentivem a inovação e promovam a melhoria da competitividade.

Assim, uma legislação como essa, bem como a própria atividade de inovar, são ações que promovem mudanças profundas na sociedade. Para que o resultado dessas mudanças seja satisfatório para a sociedade é preciso:

a) Criar um ponto de referência sobre conceitos, termos e significados relacionados à inovação (esse aspecto é complementado pela existência das normas);

b) Definir quem são os atores envolvidos, seus papeis e como podem se relacionar;

c) Regulamentar as relações público-privadas na área de inovação (essa regulamentação tem que ser pensada para reduzir as amarras sem deixar margem para os comportamentos oportunistas).

Para o Estado do Paraná, que visa atualmente evoluir no âmbito da ciência, tecnologia e inovação, é fundamental o alicerce legal, para 
garantir ambiente propício ao desenvolvimento tecnológico, impulsionando a articulação entre os atores envolvidos/agentes econômicos nesta cadeia de valor (universidades, institutos de pesquisa e setor produtivo paranaense).

Essa aspiração está fortemente pautada na Constituição Federal nos artigos 218 e 219 e a Constituição Estadual do Paraná nos artigos 200 a 205, estabelecem com um dos papéis do Estado a promoção e o incentivo ao desenvolvimento científico, a pesquisa e a capacitação tecnológica.

O evento de concepção da Lei de Inovação, no Estado do Paraná, baseouse no estudo das legislações já existentes e na experiência de profissionais que participaram da elaboração da Lei Federal e da Comissão de Estudos Especial da Associação Brasileira de Normas Técnicas (ABNT/CEE-130) que elaborou normas brasileiras (NBR) para Gestão da Pesquisa, Desenvolvimento e Inovação (PD\&I) http://www.abnt.org.br/CEE130. Desta forma, foi possível ampliar o conceito presente na maioria das leis estaduais para contemplar também as inovações organizacionais e sustentáveis.

Em resumo, os dez capítulos da lei paranaense criam os alicerces que garantem a segurança jurídica para que atores públicos e privados possam interagir e produzir conhecimentos que resultem em inovação.

A Lei, em seu Capítulo I, principia por definir sua abrangência, apresentando os conceitos centrais que vai aplicar. Desta feita permite o comum entendimento entre todos os atores sobre os termos da Lei.

Em seguida, o Capítulo II define o Sistema Paranaense de Inovação e apresenta seus integrantes.

O Sistema Paranaense de Inovação, embora já existente, ainda possui inúmeras oportunidades de melhoria. Para tanto, são necessários estímulos e direcionamentos.

O Capítulo III trata dos estímulos necessários para a construção de um verdadeiro ambiente especializado e cooperativo de inovação.

Nesse ambiente, o papel das Instituições de Ciência e Tecnologia do Estado do Paraná (ICTPR) é de protagonistas da criação de conhecimento e soluções para a sociedade em geral. O Paraná dispõe de um importante ativo de ICTPR, que pode ser utilizado para criar momento e acelerar o desenvolvimento do Estado.

O Capítulo IV detalha os usos e condições para a participação das ICTPR no processo de inovação e define os estímulos a sua participação institucional. Em particular, essas instituições dispõem de um dos insumos mais relevantes em todo processo de criação: os pesquisadores.

Por isso, o Capítulo V da Lei destaca os entendimentos sobre as condições para que os pesquisadores, em particular aqueles na condição de pesquisador instituição pública, participem do processo de inovação. De acordo com Andrade (2011), técnicos e pesquisadores responsáveis pela implementação de projetos de inovação também sofrem com os impactos da tendência de submissão da inovação a sofisticados modelos de gestão e de avaliação, por isso a importância de dar a eles a devida atenção na legislação.

Em todo Sistema Paranaense de Inovação, para que se faça jus à 
igualdade de oportunidade a todos de participar do processo de inovação.

O Capítulo VI estabelece os estímulos a participação do Inventor Independente e como este pode se beneficiar da existência de outros ativos para viabilizar a sustentabilidade de sua ideia no mercado.

O Capítulo VII é, certamente, o mais importante entre todos, pois é no estabelecimento da relação entre entidades públicas e empresas privadas que reside a maior necessidade de atenção. Primeiramente, por ter que ser sempre respeitado o interesse público, em todos os âmbitos que envolvam o aporte de recursos públicos. Mas também porque é na capacidade das empresas de atuar livremente no mercado que está a garantia das invenções tornarem-se de fato inovações.

Sem o estimulo ao empresário para que a tecnologia e o conhecimento sejam transacionados no mercado, não há Sistema de Inovação que seja sustentável. É também por meio da geração de emprego e renda nas empresas, em particular naquelas de micro e pequeno porte, que o desenvolvimento social se sustenta. Para o Paraná, é nas empresas inovadoras, de todos os portes, que o foco das políticas econômicas e industriais tem que estar centrado.

Um mecanismo útil para o estímulo a todos os atores do Sistema Paranaense de Inovação está na criação de Fundos de Investimentos. Para isso, o Capítulo VIII dispõe os termos para que isso seja possível.

Por fim, os Capítulos IX e X dispõem sobre os procedimentos de implementação da Lei e suas condições gerais, incluindo também algumas diretrizes para nortear os processos de regulamentação futuros.

Com a Lei de Inovação do Paraná são potencialmente beneficiados os profissionais que realizam pesquisa, desenvolvem projetos e de alguma forma criam o novo a partir de seu trabalho. Empresas que investem em novos produtos, novas formas de produzir, gerenciar seu negócio ou melhorar a sustentabilidade do planeta. Professores de universidades públicas e privadas que dedicam seu tempo pesquisando, criando conhecimento e solucionando problemas da sociedade. Inventores individuais, que passam a ser apoiados pelo conjunto de instituições especializadas em fomentar a inovação.

Também são beneficiadas as Instituições públicas e privadas que dedicam seu tempo à pesquisa, desenvolvimento e inovação. Uma inovação importante em relação à grande parte das leis atuais do país sobre o tema está na em estabelecer que os alunos de pós-graduação que participam diretamente de descobertas, melhorias e outras contribuições à ciência e à tecnologia durante sua formação possam ser recompensados por sua participação. Enfim, direta e indiretamente toda a sociedade se beneficia com a Lei.

O caso paranaense é emblemático para demonstrar o processo de adensamento da atividade inovadora como cerne da estratégia competitiva e de desenvolvimento. Acompanhar esse processo é agora o maior objetivo, pois dele podem-se aprender as reais oportunidade de melhoria desse instrumento e, assim, aumentar a eficiência desse tipo de intervenção no Sistema Regional de Inovação. 


\section{Considerações Finais}

Muito ainda precisa ser feito para que o Brasil atinja os níveis de produção de inovações de países como Alemanha ou Japão, mas os alicerces para essa conquista já estão sendo lançados. Mais de dois terços dos Estados da Federação realizaram algum esforço na direção de regulamentar as relações dentro de seu Sistema Regional de Inovação. Isso certamente trará frutos ao desenvolvimento regional e à consolidação do atual momento do Brasil como de prosperidade e transição definitiva para o grupo de países desenvolvidos.

Nesse cenário, o Brasil conta com um momento ímpar em termos de dinâmica populacional, pois atravessará um período onde a população economicamente ativa será preponderante. É o momento de investir maciçamente em inovação para que se possa incluir esse contingente em postos de trabalho de alto valor agregado. Assim, podemos ampliar as oportunidades de desenvolvimento do país.

A observação do caso paranaense, que pôde destacar as oportunidades de melhoria, observadas nos outros exemplos já implementados de leis estaduais, permite uma ampla gama de novos estudos sobre o tema. O principal deles seria medir os impactos reais da lei em vigor e seu reflexo no tecido produtivo do Estado do Paraná.

\section{Referências}

Andrade, Thales N. de. (2011) Tendências da inovação: estudo sociológico sobre o gerenciamento de tecnologias. São Carlos: Pedro \& João Editores.

Alvarez, Roberto dos Reis. (2010) Inovar é preciso! In: ARBIX, Glauco (org.). Inovação: estratégia de sete países. Brasília: ABDI, 2010.

Felipe, Maria Sueli Soares. (2007) Desenvolvimento tecnológico e inovação no Brasil: desafios na área de biotecnologia. Novos estud. - CEBRAP, São Paulo, n. 78, July 2007. Available from <http://www.scielo.br/scielo. php?script=sci_arttext\&pid=S0101-33002007000200002\&lng=en\&nrm=i so>. access on 10 Jan. 2012.

Instituto Brasileiro De Geografia e Estatística. Censo demográfico 2010 (resultados preliminares): características gerais da população. Disponível em: www.ibge.gov.br.

Rios-Neto, Eduardo L.G. (2009) Oportunidades perdidas e desafios críticos: a dinâmica demográfica brasileira e as políticas públicas. I Eduardo Luiz Gonçalves Rios-Neto; George Martine; José Eustáquio Diniz Alves. - Belo Horizonte: ABEP: UNFPA: CNPD, 2009.

Abati, G. Produção científica brasileira é a que mais cresce no mundo, diz presidente do CNPq. Agência Indusnet Fiesp, Acessado em 17/05/2013, 
Disponível em: http://www.fiesp.com.br/noticias/producao-cientificabrasileira-e-a-que-mais-cresce-no-mundo-diz-presidente-do-cnpq/

Taylor, Mark Zachary. Political decentralization and technological innovation: testing the innovative advantages of decentralized states. Munich Personal RePEc Archive. MPRA Paper No. 10996, posted 09. October 2008.

Terra, José C. C.; Rijnbach, Caspar B.V. Cultura de inovação. Biblioteca Terra Forum Consultores. Acesso em: 03 fev. 2012. Disponível em: <http:// biblioteca.terraforum.com.br/BibliotecaArtigo/CulturadeInovacao.pdf $>$.

Veríssimo, Michele P.; Silva, Cleomar G. da. (2011) Uma investigação sobre a hipótese de doença holandesa nas regiões brasileiras. IV Encontro Internacional da Associação Keynesiana Brasileira (AKB). 3 a 5 de agosto de 2011, Rio de Janeiro. Acesso em: 11 jan. 2012. Disponível em: http:// www.ppge.ufrgs.br/akb/encontros/2011/02.pdf. 
